\title{
Efeito de Períodos de Controle de Plantas Daninhas Sobre o Desenvolvimento Inicial de Plantas de Eucalipto ${ }^{1}$
}

\author{
Effects of Weed Control Periods on Initial Growth and Development of Eucalypt
}

TOLEDO, R.E.B. ${ }^{2}$, VICTÓRIA FILHO, R. ${ }^{3}$, PITELLI, R.A. ${ }^{4}$, ALVES, P.L.C.A. ${ }^{5}$ e LOPES, M.A.F. ${ }^{6}$

\begin{abstract}
RESUMO - O objetivo deste trabalho foi estudar os efeitos dos períodos de convivência e de controle de Brachiaria decumbens sobre o desenvolvimento inicial de clones de Eucalyptus grandis $\mathrm{x}$ Eucalyptus urophylla. Para isso, um ensaio foi conduzido, no município de Três Lagoas-MS, no período de janeiro a dezembro de 1997. Os tratamentos experimentais consistiram de diferentes épocas e períodos de convivência das plantas daninhas na cultura do eucalipto. As épocas foram divididas em dois grupos. No primeiro, a convivência se iniciava no transplante das mudas e era estendida até $28,56,84,112,140,168,224,252$ e 364 dias após. No segundo grupo, a convivência se iniciava aos 0, 28, 56, 84, 112, 140, 168, 224 e 252 dias após o transplante e era estendida até o final de um ano. As principais plantas daninhas que ocorreram na área experimental foram Brachiaria decumbens e Spermacocea latifola. As plantas jovens de eucalipto foram bastante suscetíveis à interferência das plantas daninhas, apresentando um período anterior à interferência inferior a 14-28 dias. Para assegurar o desenvolvimento da cultura, o período total de prevenção à interferência foi de 140 dias, e o período crítico de prevenção à interferência, de 14-28 a 140 dias após o transplante, considerando o índice de $5 \%$ de redução em diâmetro.
\end{abstract}

Palavras-chave: Brachiaria decumbens, eucalipto, competição, reflorestamento e interferência.

\begin{abstract}
A field trial was carried out in Três Lagoas-MS, Brazil, from January to December of 1997, to study the effects of control and coexistence period of Brachiaria decumbens on the growth of Eucalyptus grandis $x$ Eucalyptus urophylla clones. The experimental design was a complete randomized block design, with four replications. The treatments consisted of different periods of weed-eucalypt association. The periods were divided in two groups. In the first one, the weed-eucalypt coexistence initiated during the eucalypt transplanting, continuing up to $28,56,112,140,168,224,252$ and 364 days after it. In the second group, the weed coexistence began at $0,28,56,112,140,168,224$ and 252 days after the transplanting and ended 364 days later. The main infesting weeds were Brachiaria decumbens and Spermacocea latifola. The young eucalypt plants were very susceptible to weed interference. To assure normal crop development it was necessary to maintain a weed free period of 140 days after transplanting.
\end{abstract}

Key words: Brachiaria decumbens, eucalypt, competition, reforestation and interference.

\section{INTRODUÇÃO}

O Brasil ocupa o quarto lugar no mundo em implantação de maciços florestais homogêneos, sendo a sua base florestal representada por seis milhões de hectares reflorestados, com incrementos anuais em torno de 400 mil hectares (Brito, 1995).

1 Recebido para publicação em 10/9/1999 e na forma revisada em 15/12/1999.

2 Eng.-Agr ${ }^{\circ}$. M.S., Pós-graduando no curso de Fitotecnia da ESALQ/USP e bolsista da CAPES. Dep. de Horticultura. Piracicaba, SP. 13410-900; ${ }^{3}$ Prof. Titular do Dep. de Horticultura da ESALQ/USP. ${ }^{4}$ Prof.Titular do Dep. de Biologia Aplicada à Agropecuária da FCAVJ/UNESP. 14.870-000 Jaboticabal-SP; ${ }^{5}$ Prof. Dr. do Dep. de Biologia Aplicada à Agropecuária da FCAVJ/UNESP. ${ }^{6}$ Técnico Florestal da Champion Papel e Celulose Ltda., 13840-970 Mogi Guaçu-SP. 
As culturas florestais, como qualquer população natural, estão sujeitas a uma série de fatores ecológicos que, direta ou indiretamente, podem influenciar o crescimento das árvores e a produção de madeira, carvão e celulose. Esses fatores podem ser divididos em abióticos e bióticos. São considerados abióticos aqueles decorrentes da ação dos fatores físicos ou químicos do ambiente, como disponibilidade de água e nutrientes do solo, pH do solo, luminosidade e outros. Os fatores bióticos são aqueles decorrentes da ação dos seres vivos, como a competição, o comensalismo, a predação, e outros (Pitelli \& Marchi, 1991).

É importante ressaltar que o setor florestal tem se expandido em áreas de cerrado anteriormente ocupadas por pastagens, especialmente de Brachiaria decumbens. Assim, esta planta, devido à sua elevada agressividade e ao seu difícil controle, tornou-se uma das infestantes mais problemáticas nos plantios comerciais de Eucalyptus (Toledo, 1994).

O manejo das plantas daninhas em reflorestamentos, nas diversas etapas do seu processo produtivo, é realizado, basicamente, pelo emprego de métodos mecânicos e químicos, isolados ou combinados. Para que este manejo seja eficaz, faz-se necessário determinar o período, a partir do transplante, em que a cultura pode conviver com a comunidade infestante, antes que seu crescimento e sua produção sejam afetados, bem como o período em que a cultura deve ser mantida sem a presença das plantas daninhas, de modo a assegurar pleno potencial de crescimento e de produção e de forma que as plantas infestantes que emergirem após não mais concorram com a cultura do eucalipto (Toledo, 1998).

Nesse contexto, este trabalho tem por objetivo estudar os efeitos dos períodos de controle e de convivência das plantas daninhas na formação de florestas homogêneas de Eucalyptus grandis x Eucalyptus urophylla, no município de Três Lagoas-MS.

\section{MATERIAL E MÉTODOS}

Esta pesquisa foi conduzida em área experimental pertencente à Champion Papel e Celulose Ltda., localizada no município de Três
Lagoas-MS, no período de janeiro de 1997 a janeiro de 1998.

A área utilizada foi selecionada quanto à uniformidade na infestação, sendo esta representativa, considerando as áreas de produção da empresa florestal. A área era anteriormente pastagem, e, em levantamento prévio, pela técnica de amostragens aleatórias (Matteuci e Colma, 1982), foi constatado que as espécies mais freqüentes e dominantes eram o capimbraquiária ( $B$. decumbens), a erva-quente (Spermacocea latifola), a tiririca (Cyperus rotundus) e algumas rebrotas de cerrado.

Após a seleção, a área foi homogeneizada quanto à distribuição e ao estádio de desenvolvimento da comunidade infestante. Para isso, foi necessária a derrubada de árvores esparsas e a passagem de uma gradagem com máquina pesada e de uma gradagem média em área total. Em seguida, foi realizada a abertura dos sulcos e a adubação de transplante, que constituiu da distribuição, ao longo do sulco, do adubo NPK na fórmula 08-32-16 + micronutrientes $(0,5 \% \mathrm{~B} ; 0,07 \% \mathrm{Cu}$ e $0,3 \%$ de $\mathrm{Zn})$, em quantidade equivalente a $140 \mathrm{~kg} \mathrm{ha}^{-1}$. O experimento foi conduzido em um Latossolo VermelhoEscuro, textura média e álico.

As mudas de eucalipto provenientes de micropropagação obtidas no viveiro da Champion Papel e Celulose Ltda., resultantes do cruzamento entre Eucalyptus grandis $\mathrm{x}$ Eucalyptus urophylla, que apresentam rápido crescimento e tolerância a períodos mais longos de estiagem, com cerca de 100 dias de idade, foram transplantadas obedecendo a um espaçamento de 3,0 m entre plantas e 3,0 m entre linhas de transplante.

As parcelas experimentais foram constituídas, cada uma, por seis linhas de plantio com seis plantas cada, totalizando $486 \mathrm{~m}^{2}$, sendo duas linhas externas de cada lado e duas plantas de cada lado das extremidades, consideradas como bordadura, totalizando $72 \mathrm{~m}^{2} \mathrm{de}$ área útil.

Os tratamentos experimentais foram divididos em dois grupos. No primeiro, a cultura de eucalipto conviveu com a comunidade infestante por períodos crescentes desde o transplante. Após o término de cada período, que correspondia aos tratamentos experimentais, a cultura foi mantida com o mínimo 
de infestação até o final do primeiro ano. Os períodos estudados foram: $0,28,56,84,112$, 140, 168, 252 e 364 dias a partir do transplante, conforme descrito na Tabela 1 . No segundo grupo, a cultura permaneceu livre da presença das plantas daninhas por períodos crescentes, desde o transplante. Ao final de cada período, que correspondia aos tratamentos experimentais, as plantas daninhas que emergiram foram deixadas crescer livremente. Os períodos estudados neste grupo foram idênticos aos do grupo anterior.

Tabela 1 - Descrição dos tratamentos experimentais. Três Lagoas-MS. 1996/1997

\begin{tabular}{|c|c|c|}
\hline \multirow{2}{*}{ Tratamentos } & \multicolumn{2}{|c|}{ Períodos Iniciais } \\
\cline { 2 - 3 } & Sem controle & Com controle \\
\hline 1 & $0 *$ & $0-364$ \\
2 & $0-28$ & $28-364$ \\
3 & $0-56$ & $56-364$ \\
4 & $0-84$ & $84-364$ \\
5 & $0-112$ & $112-364$ \\
6 & $0-140$ & $140-364$ \\
7 & $0-168$ & $168-364$ \\
8 & $0-252$ & $252-364$ \\
9 & $0-364$ & 0 \\
10 & $28-364$ & $0-28$ \\
11 & $56-364$ & $0-56$ \\
12 & $84-364$ & $0-84$ \\
13 & $112-364$ & $0-112$ \\
14 & $140-364$ & $0-140$ \\
15 & $168-364$ & $0-168$ \\
16 & $252-364$ & $0-252$ \\
\hline
\end{tabular}

* Em número de dias após o transplante (DAT).

Os tratamentos experimentais relacionados na Tabela 1 foram dispostos no delineamento de blocos ao acaso, com quatro repetições cada; os dados obtidos foram submetidos pelo teste $\mathrm{F}$ aplicado à análise de variância, e as médias foram confrontadas pelo teste de comparação múltipla de Tukey a 5\% de probabilidade. Para determinação dos períodos de interferência, os dados de diâmetro e altura das plantas de eucalipto foram submetidos à análise de regressão e representados graficamente, segundo modelo sigmoidal de Boltzman, adaptado por Kuva (1999), sendo a equação geral: $\left.\mathbf{Y}=\left(\mathbf{A}_{\mathbf{1}}-\mathbf{A}_{2}\right) / \mathbf{\{}+\exp \left[\left(\mathbf{x}-\mathbf{x}_{0}\right) / \mathbf{d x}\right]\right\}+\mathbf{A}_{\mathbf{2}}$.
Para manutenção da cultura "no limpo", foram realizados o coroamento com capina manual nas proximidades das plantas de eucalipto e aplicações de $1,08 \mathrm{~kg}$ eq.ac. $\mathrm{ha}^{-1}$ de glyphosate, efetuadas nas entrelinhas com pulverizador costal, em jato dirigido, utilizandose bicos tipo espuma, regulado para um consumo de calda de 200 a $300 \mathrm{~L} \mathrm{ha}^{-1}$.

Aos 30, 60, 90, 120, 150, 180, 270, 330 e 360 dias após o transplante (DAT) das mudas, as oito plantas úteis de eucalipto foram avaliadas quanto ao diâmetro do caule e à altura.

Por ocasião de cada época de coroamento com capina manual, seguida da aplicação de glyphosate, foram avaliadas visualmente possiveis alterações morfofisiológicas, de crescimento e de coloração que pudessem ser caracterizadas como efeitos fitotóxicos do herbicida utilizado, baseando-se em critérios qualitativos, conforme a escala de notas da EWRC (1964), e na porcentagem de infestação (\% de cobertura do solo) nas entrelinhas de cada parcela, segundo escala de notas da ALAM (1974); foi feito também o levantamento das espécies de plantas daninhas em cada área, constando de determinação da biomassa seca, número de indivíduos e identificação.

$\mathrm{Na}$ área útil de cada parcela experimental foi amostrado $1,5 \mathrm{~m}^{2}$, correspondendo a seis subamostras de $0,25 \mathrm{~m}^{2}$, das quais três foram amostradas na linha e três na entrelinha de transplante da cultura. As espécies presentes foram contadas, identificadas e levadas ao Laboratório de Biologia e Manejo de Plantas Daninhas do Departamento de Biologia Aplicada à Agropecuária da Faculdade de Ciências Agrárias e Veterinárias de Jaboticabal, UNESP, onde foram lavadas e secas em estufa com circulação renovada de ar a $70^{\circ} \mathrm{C}$. Após este procedimento, foi determinada a biomassa seca da parte aérea das espécies coletadas, utilizando-se balança elétrica com precisão de 0,01 g.

\section{RESULTADOS E DISCUSSÃO}

A principal espécie de planta daninha presente na área experimental foi o capim-braquiária (Brachiaria decumbens), acumulando, em média, $1.556,14 \mathrm{~g} \mathrm{~m}^{-2}$ da biomassa seca na área total da parcela da testemunha "no mato", distribuída da seguinte forma: 546,65 $\mathrm{g} \mathrm{m}^{-2}$ na linha 
e $1.009,49 \mathrm{~g} \mathrm{~m}^{-2}$ na entrelinha de transplante do eucalipto. Por outro lado, toda a comunidade infestante, constituída ainda por tiririca $(C$. rotundus), erva-quente ( $S$. latifola), malva-vermelha (C. glandulosus) e algumas rebrotas de cerrado, acumulou, em média, 1.652, $14 \mathrm{~g} \mathrm{~m}^{-2}$, sendo 561,58 $\mathrm{g} \mathrm{m}^{-2}$ na linha e 1.090,56 $\mathrm{g} \mathrm{m}^{-2}$ na entrelinha de transplante.

Pelos dados da Figura 1, pode-se observar a densidade do capim-braquiária em relação a outras plantas daninhas, nos diferentes tratamentos utilizados. Os dados de precipitação pluvial na Figura 2 influenciaram a ocorrência do capim-braquiária no período experimental.

A densidade média do capim-braquiária encontrada nas parcelas em que as plantas de eucalipto conviveram por 364 dias com a comunidade infestante foi aproximadamente de 32 plantas $/ \mathrm{m}^{2}$ na área total, distribuídas em 16 plantas $/ \mathrm{m}^{2}$ na linha e na entrelinha de transplante do eucalipto (Figura 1). Já a densidade total da comunidade em área total foi de 40 plantas $/ \mathrm{m}^{2}$, distribuídas uniformemente na linha e na entrelinha da cultura (20 plantas $/ \mathrm{m}^{2}$ ), conforme pode ser observado na Figura 1, situação comum em muitas áreas reflorestadas no País, o que confere boa representatividade dos dados obtidos na presente pesquisa.

Bezutte et al. (1995a) observaram que, a partir de 4 plantas $/ \mathrm{m}^{2}$, o capim-braquiária interfere significativamente no crescimento inicial das mudas de eucalipto, reduzindo em média $27,78 \%$ o diâmetro e $18,47 \%$ a altura das plantas, aos 190 DAT. Portanto, as densidades médias observadas neste trabalho justificam a necessidade de controle das plantas daninhas.

No decorrer do período experimental, não se observou qualquer sintoma de injúria nas plantas de eucalipto - quando devidamente coroadas - decorrente dos tratamentos, o que, segundo a escala da EWRC (1964), corresponde à nota 1 , ou seja, injúria nula.

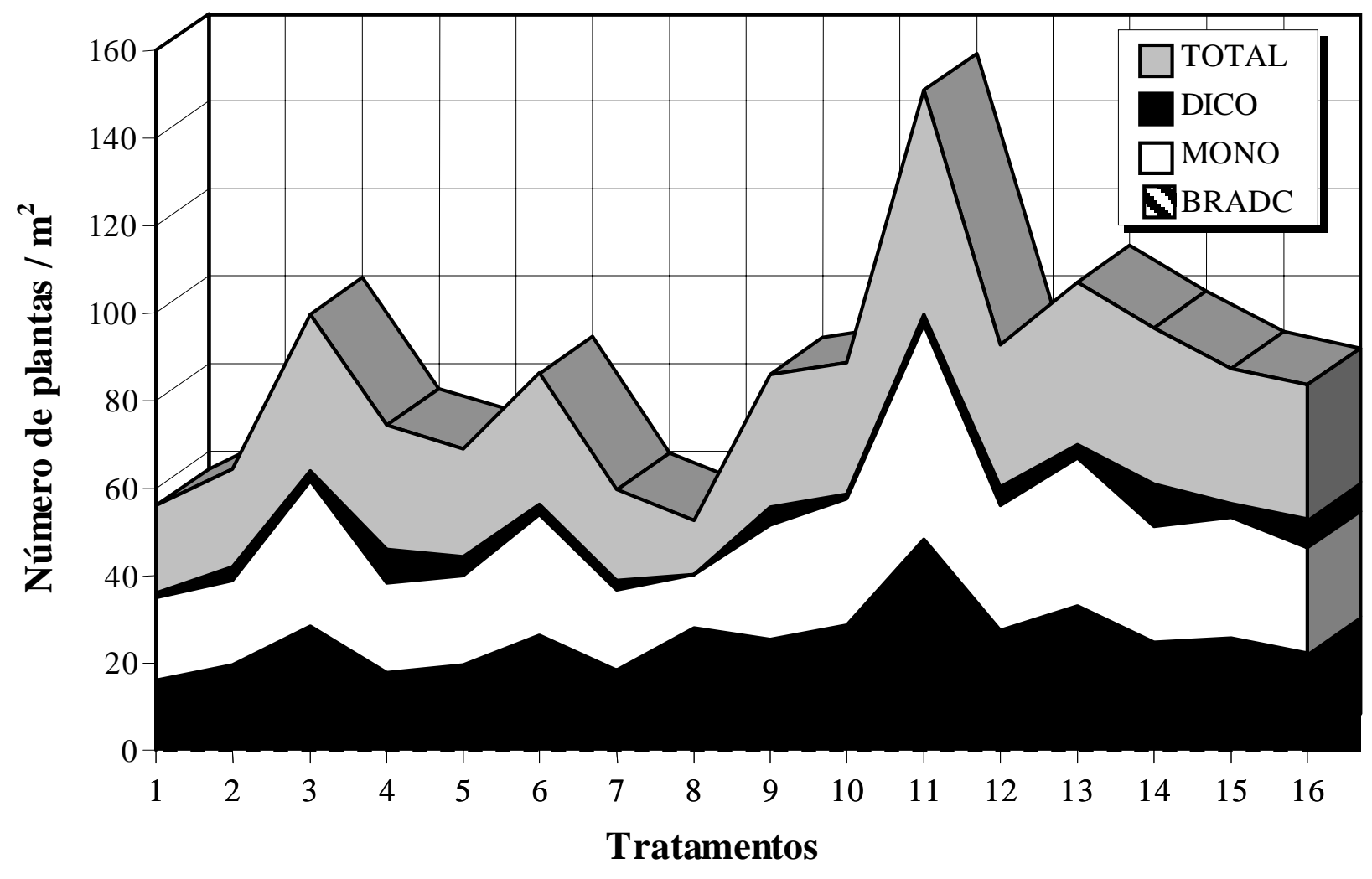

Figura 1 - Densidade das principais espécies de plantas daninhas presentes na área total da cultura. Três Lagoas-MS. 1996/1997. 


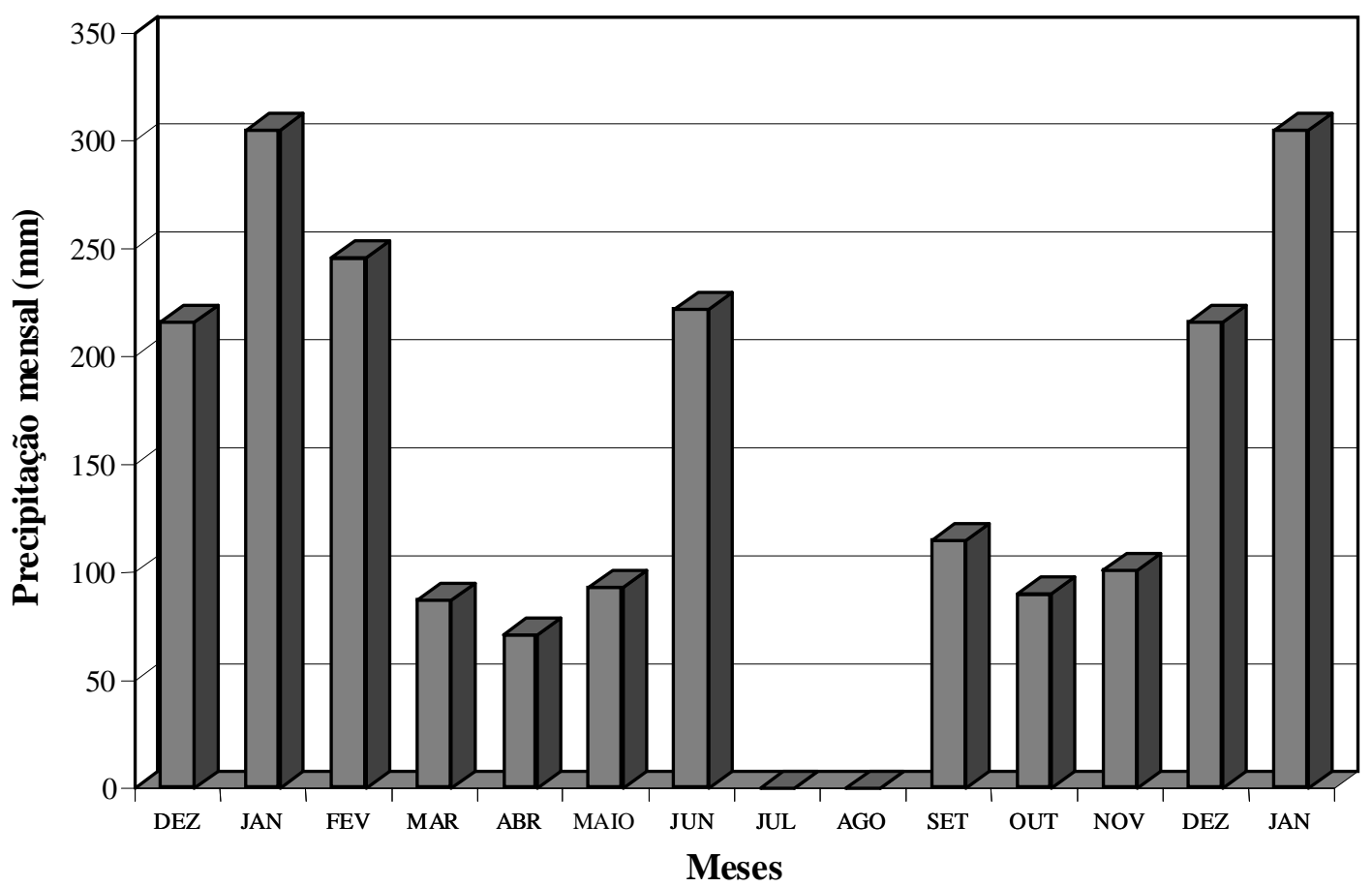

Figura 2 - Precipitação pluvial mensal ocorrida na área experimental. Três Lagoas-MS. 1996/1997.

Nas Figuras 3 e 4 estão representados graficamente os valores de diâmetro do caule e altura das plantas de eucalipto, respectivamente, durante o primeiro ano de crescimento, nas duas situações de crescimento da espécie florestal, ou seja, na presença e na ausência da comunidade infestante. Pode-se notar que tanto o diâmetro do caule como a altura das plantas de eucalipto foram reduzidos pela presença das plantas daninhas. Aos 364 dias de convivência, as plantas de eucalipto que cresceram em convivência com a comunidade infestante em todo o período experimental apresentaram diâmetro médio de $2,12 \mathrm{~cm}$ e altura de $1,61 \mathrm{~m}$, o que representa $29,44 \%$ do diâmetro e $31,45 \%$ da altura média das plantas de eucalipto que cresceram livres da interferência das plantas daninhas por todo o período experimental, as quais apresentaram $7,20 \mathrm{~cm} \mathrm{e}$ $5,12 \mathrm{~m}$, respectivamente (Tabela 2). Essas diferenças se deveram à alta pressão de interferência exercida pelas plantas daninhas, especialmente o capim-braquiária. Essa resposta em relação à altura das plantas de eucalipto não era esperada, uma vez que a altura das plantas não constitui característica adequada para avaliação dos dados de competição (Rodrigues et al., 1991).

Desse modo, Pitelli \& Marchi (1991) comentam que, sob intensa infestação de plantas daninhas, o eucalipto tende a perder rapidamente os ramos e as folhas da base da copa, apresentando, com isso, pequena quantidade de folhas concentradas no topo da muda e provocando o estiolamento da muda, devido à competição por luz, que restringe a fonte predominante de energia aos processos básicos de recrutamento de elementos e de elaboração de todas as substâncias envolvidas no crescimento do vegetal.

Apesar da pequena diferença na porcentagem de redução $(70,43 \%$ em diâmetro e $68,56 \%$ em altura), pode-se dizer que o diâmetro do caule foi mais afetado pela presença das plantas daninhas do que a altura das plantas de eucalipto, principalmente nos períodos de 28 a 84 dias de convivência. Tanto o diâmetro do caule como a altura das plantas de eucalipto passaram a ser expressivamente influenciados pela comunidade infestante a partir da avaliação de 28 dias (Figuras 3 e 4). 


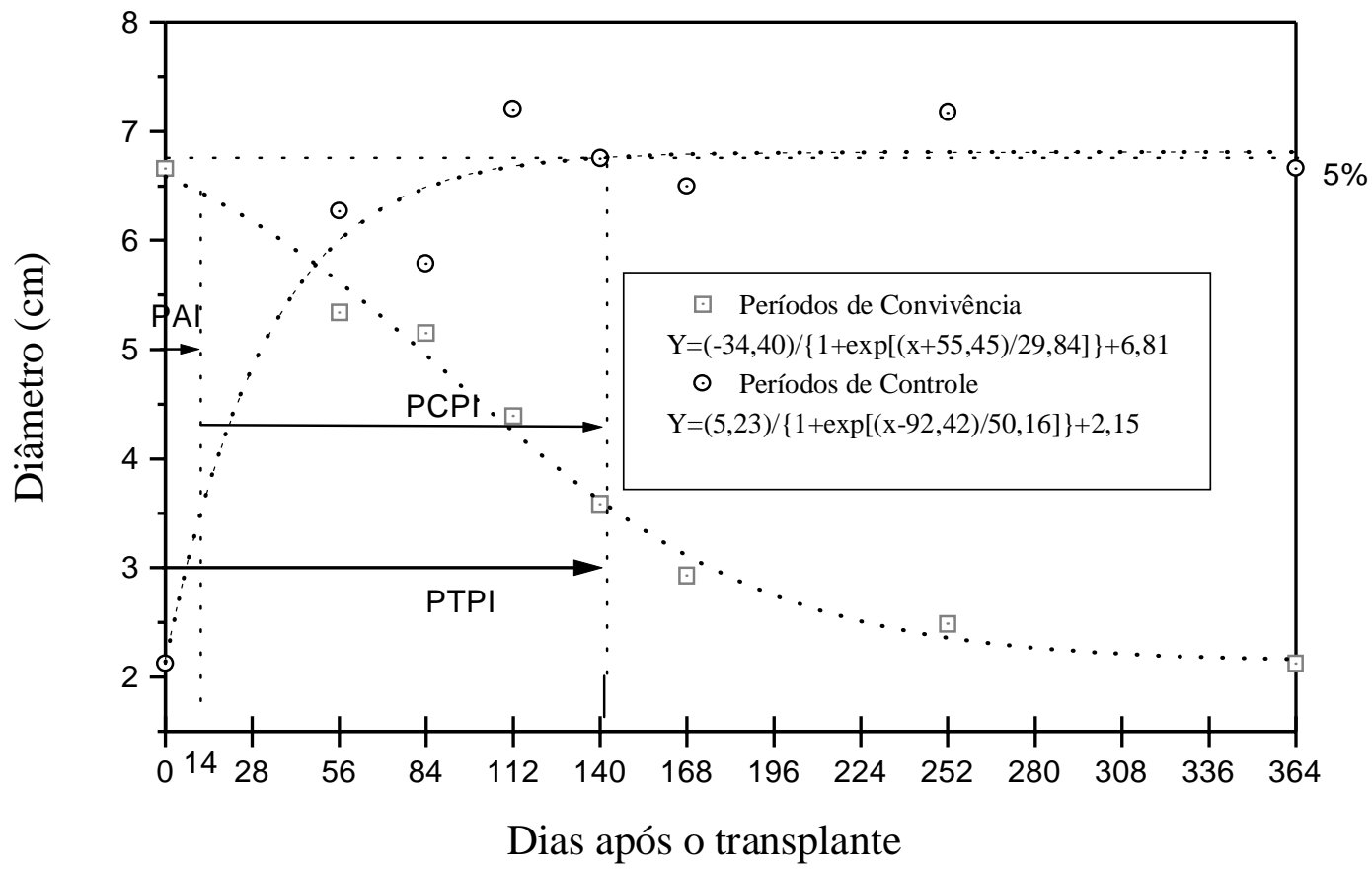

Figura 3 - Evolução do diâmetro do caule $(\mathrm{cm})$ de clones de eucalipto sob diferentes situações e períodos de convivência e de controle das plantas daninhas na área experimental. Três Lagoas-MS. 1996/1997.

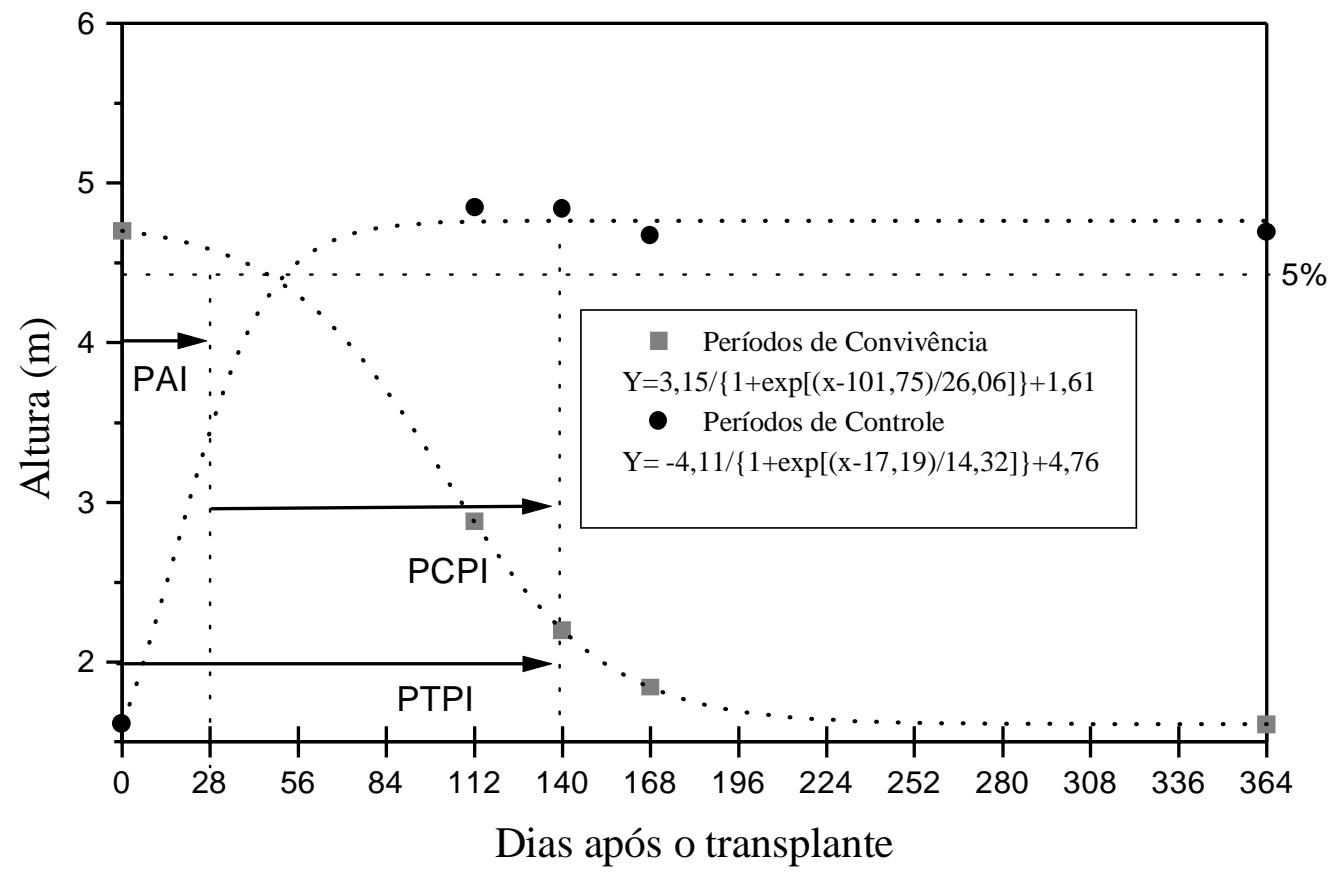

Figura 4 - Evolução da altura (m) de clones de eucalipto sob diferentes situações e períodos de convivência e de controle das plantas daninhas na área experimental. Três Lagoas-MS. 1996/1997. 
Tabela 2 - Efeito dos diferentes períodos de convivência e de controle da comunidade infestante sobre o diâmetro do caule $(\mathrm{cm})$ e a altura $(\mathrm{m})$ de clones de eucalipto, avaliados aos 12 meses de idade da cultura. Três Lagoas-MS. 1997

\begin{tabular}{|c|c|c|c|c|}
\hline \multirow{2}{*}{ Tratamentos } & \multicolumn{2}{|c|}{ Períodos Iniciais } & Diâmetro & Altura \\
\cline { 2 - 3 }$(\mathrm{cm})$ & Sem Controle & Com controle & $(\mathrm{cm})$ & $(\mathrm{m})$ \\
\hline 1 & $0^{1}$ & $0-364$ & $6,66 \mathrm{ab}^{2}$ & $4,70 \mathrm{ab}$ \\
2 & $0-28$ & $28-364$ & $6,38 \mathrm{abc}$ & $4,37 \mathrm{abc}$ \\
3 & $0-56$ & $56-364$ & $5,34 \mathrm{cde}$ & $3,80 \mathrm{~cd}$ \\
4 & $0-84$ & $84-364$ & $5,15 \mathrm{de}$ & $3,39 \mathrm{de}$ \\
5 & $0-112$ & $112-364$ & $4,39 \mathrm{ef}$ & $2,88 \mathrm{ef}$ \\
6 & $0-140$ & $140-364$ & $3,58 \mathrm{fg}$ & $2,20 \mathrm{fg}$ \\
7 & $0-168$ & $168-364$ & $2,83 \mathrm{gh}$ & $1,84 \mathrm{~g}$ \\
8 & $0-252$ & $252-364$ & $2,49 \mathrm{~h}$ & $1,67 \mathrm{~g}$ \\
9 & $0-364$ & 0 & $2,12 \mathrm{~h}$ & $1,61 \mathrm{~g}$ \\
10 & $28-364$ & $0-28$ & $5,92 \mathrm{bcd}$ & $4,19 \mathrm{bcd}$ \\
11 & $56-364$ & $0-56$ & $6,08 \mathrm{bcd}$ & $4,37 \mathrm{abc}$ \\
12 & $84-364$ & $0-84$ & $5,79 \mathrm{bcd}$ & $4,22 \mathrm{bc}$ \\
13 & $112-364$ & $0-112$ & $7,20 \mathrm{a}$ & $4,85 \mathrm{ab}$ \\
14 & $140-364$ & $0-140$ & $6,75 \mathrm{ab}$ & $4,84 \mathrm{ab}$ \\
15 & $168-364$ & $0-168$ & $6,50 \mathrm{ab}$ & $4,67 \mathrm{ab}$ \\
16 & $252-364$ & $0-252$ & $7,17 \mathrm{a}$ & $5,12 \mathrm{a}$ \\
\hline $\mathrm{F}_{\text {tratamennos }}$ & & & $68,28 * *$ & $60,54 * *$ \\
$\mathrm{~F}_{\text {bbcos }}$ & & & $2,85 *$ & $7,86 * *$ \\
$\mathrm{DMS}$ & & & 1,0482 & 0,8143 \\
$\mathrm{CV}(\%)$ & & & 7,76 & 8,66 \\
\hline
\end{tabular}

Em número de dias após o transplante (DAT).

2 Médias seguidas de mesma letra não diferem significativamente entre si pelo teste de Tukey a $1 \%$ de probabilidade.

* Significativo a $5 \%$ de probabilidade.

De modo geral, pode-se dizer que, quanto maior for o período de convivência entre a cultura e a comunidade infestante, maior será o grau de interferência. No entanto, segundo Pitelli (1987), isto não é totalmente válido, porque dependerá da época do ciclo da cultura em que este período for considerado. Os períodos encontrados por diferentes autores não são idênticos, o que pode ser explicado pelo fato de as condições de condução das pesquisas, as próprias espécies ou variedades utilizadas e as composições específicas das comunidades infestantes serem diferentes. Dada a diversidade dos fatores que influenciam o grau e os períodos de interferência, torna-se extremamente importante que estes estudos se intensifiquem e ultrapassem os limites dos Centros de Pesquisas e Universidades, sendo executados pelas empresas florestais que pretendam informações mais significativas para as suas áreas de produção.

Na cultura de Eucalyptus são poucos os estudos sobre os períodos considerados críticos nas suas relações de interferência com a comunidade infestante. Andrade (1961) afirma que o eucalipto é uma planta delicada, sensível à interferência da comunidade infestante e sugere que a cultura seja mantida com o mínimo de infestação nos dois primeiros anos. Osse (1961) sugere que o período de controle deva ser maior quando as florestas são infestadas por gramíneas e polipodiáceas.

Zen (1987) observou que, em áreas infestadas por samambaias (Pteridium aquilinum(L.) Kuhn.), o controle de plantas daninhas por 60 dias assegurou o crescimento e que o diâmetro do caule de $E$. grandis foi estatisticamente semelhante ao da testemunha "no limpo".

Estudos conduzidos por Pitelli et al. (1988), no município de João Pinheiro-MG, mostraram que os efeitos da interferência das plantas infestantes sobre a altura das plantas de eucalipto foram bastante evidentes, caracterizando um período anterior à interferência de 105 dias. No entanto, a análise de regressão polinomial dos dados sugere que os efeitos negativos da convivência das plantas daninhas se iniciam aos 17 dias, com forte componente linear até os 245 dias.

Kogan et al. (1995), em experimentos realizados com Eucalyptus nitens no período de 1993/94, observaram que, tanto para os plantios de outono como para os de primavera, as plantas daninhas iniciaram a interferência muito precocemente; bastaram somente 30 dias de convivência para que proporcionassem reduções de 20-50\% na área de secção $\left(\mathrm{D}^{2} \mathrm{H}\right)$. O período total de prevenção (PTPI) na plantação de outono (maio de 1993) foi de aproximadamente 240-250 dias. Isso indicaria que, logo após o plantio seria necessário manter-se a cultura livre das plantas daninhas por um período de pelo menos oito meses, a fim de se obter um máximo de área de secção $\left(\mathrm{D}^{2} \mathrm{H}\right)$. No entanto, o PTPI na plantação de primavera (setembro de 1993) foi menor, indicando que logo após o plantio das mudas seria necessária a manutenção destas, sem a presença da comunidade infestante, por um período de quatro meses para assegurar uma adequada área de secção.

Em trabalho realizado no município de Viçosa-MG, Pitelli et al. (1988) observaram, para mudas de E. urophylla, um período anterior à 
interferência (PAI) de 30 dias, embora a tendência estatística sugerisse efeitos prejudiciais da comunidade infestante desde o início da implantação da cultura. O período total de prevenção à interferência (PTPI) foi de 60 dias, apesar de a tendência estatística ter sugerido efeitos positivos do controle de plantas daninhas até 105 dias.

Bezutte et al. (1995b), considerando plantas de E. grandis com três anos de idade, verificaram que elas, durante sua fase inicial de desenvolvimento, podiam conviver com o capim-braquiária (B. decumbens) e o capimbraquiarão ( $B$. brizantha) até 56 dias sem comprometer a sua produção, aos três anos de idade (PAI). Por outro lado, foi necessário que a cultura fosse mantida "no limpo" por um período de 168 dias para que a sua produtividade, aos três anos, não fosse comprometida (PTPI). Os resultados observados por estes autores evidenciaram a grande interferência promovida por essas plantas daninhas no início de desenvolvimento da cultura do eucalipto e que a capacidade da cultura recuperar-se em períodos posteriores é pequena.

Marchi (1996) observou que os maiores ganhos de crescimento da cultura do eucalipto foram obtidos com o controle do capim-colonião (Panicum maximum) nos primeiros 100 a 120 dias. As plantas de eucalipto que conviveram com periodos superiores a 84 dias apresentaram redução de produção de madeira de até $67 \%$ aos 1,8 ano de idade e $50 \%$ aos 2,6 anos. A análise de custo-benefício, realizada pelo autor, revelou que uma capina manual logo no início da instalação da cultura com duas subseqüentes aplicações de oxyfluorfen, visando um período residual acima de 100 dias, proporcionou aceitável produção de madeira a um baixo custo, gerando uma relação custo-benefício positiva já aos 2,6 anos de idade da cultura, quando comparada com a testemunha que conviveu na presença das plantas daninhas por 364 dias.

Toledo et al. (1996), ao estudarem os custos das diversas atividades de implantação de um hectare de $E$. grandis, constataram que a atividade mais onerosa no primeiro ano da instalação da cultura é o controle das plantas daninhas, com o capim-braquiária na entrelinha da cultura através de quatro capinas manuais representando $30,7 \%$ dos custos totais de implantação, enquanto a aplicação de glyphosate em três ocasiões representou $17,3 \%$ do total gasto. Os mesmos autores ainda observaram que, de maneira geral, os custos de controle das plantas daninhas totalizaram cerca de $66 \%$ do custo total de implantação da floresta, independentemente do tipo de manejo adotado.

Pelos resultados obtidos nas condições de execução deste trabalho, pode-se afirmar que o período em que a cultura do eucalipto pode conviver com a comunidade infestante a partir do transplante, antes que a interferência se instale de maneira definitiva e reduza significativamente o seu desenvolvimento inicial, é de 14-28 dias, sendo denominado período anterior à interferência (PAI) (Figuras 3 e 4). Teoricamente, o final do período anterior à interferência seria a época ideal para o primeiro controle da comunidade infestante, pois a comunidade teria acumulado uma quantidade de energia e de biomassa que retornaria ao solo, contribuindo para o próprio desenvolvimento da cultura. No entanto, na prática, geralmente este período não pode ser considerado, pois a cultura e/ou as plantas daninhas podem ter atingido um estádio de desenvolvimento que inviabilize o uso de práticas mecânicas ou o controle químico (Pitelli, 1987).

O período a partir do transplante da cultura em que a cultura do eucalipto deve ser mantida livre da presença da comunidade infestante, a fim de que a sua produção não seja afetada quantitativa e/ou qualitativamente, denominado período total de prevenção à interferência (PTPI), é de 140 dias após o transplante (Figuras 3 e 4). Na prática, este deve ser o período em que as capinas ou o poder residual do herbicida devem abranger, pois as espécies infestantes que emergirem neste período, em determinada época do ciclo da cultura, terão atingido tal estádio de desenvolvimento que promoverão interferência capaz de reduzir significativamente a produtividade econômica do eucalipto (Pitelli, 1987).

A época ideal de controle das plantas daninhas neste trabalho deve ser realizada imediatamente antes que os recursos do meio sejam disputados pela cultura e a comunidade infestante, prolongando-se até o período em que as 
plantas infestantes que emergirem após não mais concorram com a cultura do eucalipto, denominado período crítico de prevenção à interferência (PCPI), que corresponde de 1428 a 140 dias após o transplante (Figuras 3 e 4). Em resumo, pelos resultados obtidos nas condições de execução em que foi desenvolvida esta pesquisa, pode-se concluir que as plantas daninhas passam a reduzir significativamente o crescimento das plantas de eucalipto a partir de 14-28 dias de convivência e que é necessário um período de 140 dias de controle para assegurar o pleno crescimento da cultura no primeiro ano de seu ciclo de desenvolvimento.

\section{AGRADECIMENTOS}

Ao convênio Champion Papel e Celulose Ltda. /ESALQ-USP e CAPES, pela concessão de bolsas de estudo.

\section{LITERATURA CITADA}

ASSOCIACION LATINOAMERICANA DE MALEZAS - ALAM. Recomendaciones sobre unificacion de los sistemas de evaluacion em ensayos de control de malezas. ALAM, v.1, p.35-38, 1974.

ANDRADE, E.D. O eucalipto. 2.ed. Jundiaí: Cia Paulista de Estradas de Ferro, 1961. 665p.

BEZUTTE, A.J., TOLEDO, R.E.B, PITELli, R.A, ALVES, P.L.C.A."Efeito da densidade de plantas de Brachiaria decumbens sobre o crescimento inicial de Eucalyptus grandis". In: CONGRESSO BRASILEIRO DA CIENCIA DAS PLANTAS DANINHAS, 20, 1995. Florianópolis. Resumos... Florianópolis: 1995a. p.272-273.

BEZUTTE, A.J., TOLEDO, R.E.B, PITELLI, R.A, ALVES, P.L.C.A., ALVARENGA, S.F., CORRADINE, L. "Efeito de períodos de convivência de Brachiaria decumbens no crescimento inicial de Eucalyptus grandis e seus reflexos na produtividade da cultura aos três anos de idade." In: CONGRESSO BRASILEIRO DA CIÊNCIA DAS PLANTAS DANINHAS, 20, 1995, Florianópolis. Resumos... Florianópolis: 1995b. p.272-273.

BRITO, M.A.R. Manejo de Plantas Daninhas em Áreas de Reflorestamento. In: CONGRESSO BRASILEIRO DA CIÊNCIA DAS PLANTAS DANINHAS, 20, 1995. Florianópolis. Resumos de Palestras... Florianópolis: 1995. p. 92-95.
EUROPEAN WEED RESEARCH COUNCIL - EWRC. Report of the $3^{\text {rd }}$ and $4^{\text {th }}$ meetings of EWRC. Comittee of Methods in Weed Research. Weed. Res., v.4, p.88, 1964.

KOGAN, M.A., OlATE, E., FIGUEROA, R. Período critico de control de malezas en el establecimento del eucalipto. In: CONGRESSO LATINOAMERICANO DE MALEZAS, 12, 1995. Montevideo. Anales... Montivideo: 1995, 136p.

KUVA, M.A. Efeito de períodos de controle e de convivência das plantas daninhas na cultura da cana-de-açúcar (Saccharum sp.) no estado de São Paulo. Piracicaba, ESALQ 1999. 74p. Dissertação (Mestrado em Fitotecnia) - Escola Superior de Agricultura “Luiz de Queiroz”, 1999.

MARCHI, S.R. Efeitos de períodos de convivência e de controle das plantas daninhas sobre o crescimento inicial e a composição mineral de Eucalyptus grandis W. Hill ex Maiden. Jaboticabal: UNESP, 1996. 94p. Dissertação (Mestrado em Fitotecnia) - Universidade Estadual Paulista “Júlio de Mesquita Filho”, 1996.

MATTEUCCI, S.D., COLMA, A. Methodologia para el estudio de la vegetation. Washington: OEA, 1982, 168p. (Série de Biologia Monografia, 22).

OSSE, L. As culturas de eucalipto da Ciza. Siderúrgica Belgo Mineira. An. Bras. Econ. Flor., v.13, p.102-112, 1961.

PITELLI, R.A. Competição e controle das plantas daninhas em áreas agrícolas. In: SEMINÁRIO TÉCNICO SOBRE HERBICIDAS EM REFLORESTAMENTO, Piracicaba, 1986. IPEF - Série Téc., v.4, n.12, p.25-35, 1987.

PITELLI, R.A., MARCHI, S.R. Interferência das plantas invasoras nas áreas de reflorestamento. In: SEMINÁRIO TÉCNICO SOBRE PLANTAS DANINHAS E O USO DE HERBICIDAS EM REFLORESTAMENTO, 3, 1991, Belo Horizonte. Anais... Belo Horizonte: 1991. p.1-11.

PITELLI, R.A., RODRIGUES, J.J.V., KARAM, D., COELHO, J.P., ZANUNCIO, I., ZANUNCIO, C.C. Efeitos de períodos de convivência e do controle de plantas daninhas na cultura de Eucalyptus. In: SEMINÁRIO TÉCNICO SOBRE PLANTAS DANINHAS E O USO DE HERBICIDAS EM REFLORESTAMENTO, 1, 1988, Rio de Janeiro. Anais... Rio de Janeiro: 1998. p.110-123. 
RODRIGUES, J.J.V., COELHO, J.P., PITELLI, R.A. Efeitos de períodos de controle de convivência do capim-colonião (Panicum maximum) na cultura do Eucalyptus. In: SEMINÁRIO TÉCNICO SOBRE PLANTAS DANINHAS E O USO DE HERBICDAS EM REFLORESTAMENTO, 3, 1991, Belo Horizonte. Anais... Belo Horizonte: 1991. p.43-54.

TOLEDO, R.E.B. Manejo de Brachiaria decumbens Stapf. em área reflorestada com Eucalyptus grandis W. Hill ex Maiden e seu reflexo no crescimento e nutrição mineral da cultura. Jaboticabal: UNESP, 1994. 162p. Monografia (Graduação) - Universidade Estadual Paulista "Julio de Mesquista Filho", 1994.
TOLEDO, R.E.B., ALVES, P.L.C.A., VALLE, C.F., ALVARENGA, S.F. Comparação dos custos de quatro métodos de manejo de Brachiaria decumbens Stapf. em área reflorestada com Eucalyptus grandis W. Hill ex Maiden. R. Árv., v.20, n.3, p.319-330, 1996.

TOLEDO, R.E.B. Efeitos da faixa de controle e dos períodos de controle e de convivência de Brachiaria decumbens Stapf no desenvolvimento inicial de plantas de $x$ Eucalyptus urograndis. Piracicaba: ESALQ, 1998. 71 p. Dissertação (Mestrado em Fitotecnia) - Escola Superior de Agricultura "Luiz de Queiroz", 1998.

ZEN, S. Influência da matocompetição em plantas de Eucalyptus grandis. IPEF. Série Téc., n.12, p.25-35, 1987. 